\title{
ESTADO-NAÇÃO E AS LUTAS POR AUTONOMIA E DIREITOS DOS POVOS TRADICIONAIS NA AMÉRICA LATINA: ALTERNATIVAS DESDE O NOVO CONSTITUCIONALISMO DEMOCRÁTICO LATINO-AMERICANO
}

\section{João Vitor Martins Lemes ${ }^{1}$ Bárbara Luiza Ribeiro Rodrigues ${ }^{2}$}

RESUMO: A partir da segunda metade do século XX, o modelo de Estado estabelecido na América Latina por herança colonial passa a ser questionado pelos povos tradicionais e originários que começam a reivindicar, a partir das premissas da autonomia e da interculturalidade, um novo modelo de Estado-nação que, num sentido emancipador, considere as diferenças dos contextos locais. O presente trabalho reflete sobre a dinâmica de construção da noção e simbologia do Estado-nação e seu questionamento por parte dos povos e comunidades tradicionais, apresentando, como exemplo, as alternativas apresentadas desde o novo constitucionalismo democrático latino-americano.

PALAVRAS-CHAVE: Autonomia dos povos tradicionais; Estado; Interculturalidade; Novo Constitucionalismo Latino-americano.

\section{STATE AND THE STRUGGLES FOR AUTONOMY AND RIGHTS OF TRADITIONAL COMMUNITIES IN LATIN AMERICA: ALTERNATIVES SINCE THE NEW LATIN AMERICAN DEMOCRATIC CONSTITUTIONALISM}

ABSTRACT: From the second half of the twentieth century onwards, the state model established in Latin America by colonial heritage is questioned by the traditional and original peoples who begin to claim, from the premises of autonomy and interculturality, a new model of State- a nation that, in an emancipatory sense, considers the differences of local contexts. The present work reflects on the dynamics of construction of the notion and symbology of the nation-state and its questioning by the traditional peoples and communities, presenting, as an example, the alternatives presented since the new Latin American democratic constitutionalism.

KEYWORDS: Autonomy of traditional communities; State; Interculturality; New Latin American Constitutionalism.

\footnotetext{
1 Doutorando em Antropologia Social e Mestre em Direito Agrário pela Universidade Federal de Goiás. Pesquisador e extensionista do Observatório Fundiário Goiano. Professor Assistente no curso de Direito da Universidade Federal do Tocantins, Campus Arraias

${ }^{2}$ Mestra em Direito Agrário pela Universidade Federal de Goiás. Pesquisadora do Observatório Fundiário Goiano. Professora na Faculdade Evangélica de Goianésia (FACEG), mantida pela Associação Educacional Evangélica (AEE), onde desempenha os cargos de Assessora da Coordenação de Pesquisa e de Assessora da Coordenação de Ensino, responsável pelo Núcleo de Atividades Interdisciplinares (NUAI).
} 


\title{
INTRODUÇÃO
}

\author{
"Nosotras y nosotros, el pueblo soberano del Ecuador, \\ RECONOCIENDO nuestras raíces milenarias, \\ forjadas por mujeres y hombres de distintos pueblos, \\ CELEBRANDO a la naturaleza, la Pacha Mama, \\ de la que somos parte y que es vital para nuestra existencia, \\ INVOCANDO el nombre de Dios y reconociendo nuestras \\ diversas formas de religiosidad y espiritualidad, \\ APELANDO a la sabiduría de todas las culturas \\ que nos enriquecen como sociedad, \\ COMO HEREDEROS de las luchas sociales de liberación \\ frente a todas las formas de dominación y colonialismo, \\ $Y$ con un profundo compromiso con el presente y el futuro,
}

Decidimos construir

Una nueva forma de convivencia ciudadana, en diversidad y armonía con la naturaleza, para alcanzar el buen vivir, el sumak kawsay;

Una sociedad que respeta, en todas sus dimensiones, la dignidad de las personas y las colectividades; Un país democrático, comprometido con la integración latinoamericana - sueño de Bolívar y Alfaro - la paz y la solidaridad con todos los pueblos de la tierra".

- Preâmbulo da Constituição Equatoriana de 2008

O novo constitucionalismo democrático latino-americano é um movimento que, ao admitir novas subjetividades no seio do Estado-nação e atribuir às mesmas participação e direitos antes não reconhecidos, rompe com o modelo de Estado-nação forjado nos moldes da modernidade, sobretudo a partir dos princípios fundantes da Revolução Francesa. Esse modelo dos primados da modernidade, fundado em elementos-chave como identidade, pertencimento e homogeneidade, elege grupos e indivíduos específicos como titulares possíveis das relações sociais no âmbito do Estado, atribuindo às demais pessoas e comunidades a tarefa de adaptação frente ao padrão estabelecido.

Conforme pondera Abrams (2015), esse padrão de dominação do Estado funciona no sentido de situar todo o corpo da sociedade segundo as noções de unidade, moral e dependência. Assim, todos os indivíduos que não se enquadram no padrão do sujeito capaz de se relacionar no âmbito do Estado necessitam de transformar suas subjetividades de forma a enquadraremse nas mesmas condições dos setores e indivíduos detentores da condição de sujeitos reconhecidos pelo Estado ou serão tratados na perspectiva de marginalização e invisibilização na estrutura estatal. 
Importado em razão da conquista e colononização, esse modelo de Estado que já invisibilizava e marginalizava indivíduos e grupos na Europa ganhou contornos mais graves na América Latina, uma vez que encontrou aqui grupos e indivíduos ainda mais divergentes aos sujeitos de direito do Estado Moderno europeu. Em razão do projeto de dominação do Estado nas colônias latino-americanas, inúmeras comunidades e indivíduos que apresentaram resistência e discordância em relação ao novo modelo de organização apresentado pelos conquistadores foram dizimados ao longo dos últimos séculos.

$\mathrm{Na}$ tentativa de irromper com essa realidade, fruto das lutas por autonomia e direitos decorrente da resistência de diversos grupos, sobretudo da região dos Andes, os processos constituintes de alguns Estados latino-americanos passam a inovar na perspectiva das titularidades jurídicas e a questionar o modelo de Estado forjado nos moldes da modernidade, exigindo o reexame da teoria do Estado e do direito no tocante às matrizes essenciais que fundam esse modelo, de modo a reconhecer a existência de indivíduos que não se enquadram nos padrões concebidos a partir da noção de uniformização e homogeneidade da sociedade nacional e que foram mantidos na estrutura estatal numa perspectiva de negação, invisibilização e marginalização.

Esse movimento se soma a inúmeros outros América Latina afora que se caracterizam pela luta dos povos e comunidades tradicionais na busca por autonomia, participação e direitos, tendo como fundamentos a interculturalidade e a pluralidade de povos, nações e direitos, demandando do Estado muito mais do que os primados da modernidade, do liberalismo e do neoliberalismo têm a oferecer, reafirmando a proposta de Dussel (2007), segundo a qual a América Latina deve reconhecer-se como continente gerador de novos pensamentos, para fundar suas propostas respeitantes a todas as existências sujeitas aos direitos. Afirmar e garantir essas novas subjetividades perpassa necessariamente, então, descolonizar a noção de Estado, forjando novos modelos que se adequem aos contextos próprios e à pluridiversidade de sujeitos e culturas característica dos Estados nacionais latino-americanos.

Nesse sentido, objetivando estabelecer um caráter linear e coeso às reflexões aqui propostas o texto está estruturado em três partes: a primeira parte, o "Estado-Nação e a negação das autonomias e direitos" apresenta a construção da noção de Estado e sua réplica na América Latina a partir da ordem colonial aqui estabelecida, destacando como essa estrutura ocupa um lugar de limitação e opressão das subjetividades que divergem da figura do indivíduo padrão eleito enquanto capaz frente ao Estado. 
A segunda parte, intitulada "As lutas por autonomia e direitos e a democracia comunitária como projeto" pretende refletir sobre a reação desses sujeitos não reconhecidos pelo Estado frente a essa estrutura a partir de processos de mobilização e construção de soluções que resultem na afirmação da autonomia e na garantia de direitos, embasadas na noção de democracia comunitária.

Por fim, a terceira parte demonstra, desde a experiência do novo constitucionalismo democrático latino-americano, sobremaneira a partir dos casos da Bolívia e do Equador, as possibilidades de reestruturação do Estado nacional a partir de processos de reconhecimento da existência de diversos sujeitos, culturas e racionalidades numa mesma nação, assumindo, assim, a interculturalidade um status essencial dos novos textos constitucionais e, consequentemente, dos Estados latino-americanos.

\section{I - O ESTADO-NAÇÃO E A NEGAÇÃO DAS DIVERSIDADES, SUBJETIVIDADES E AUTONOMIAS}

A noção de Estado-nação, cujas principais características são estabelecidas com o advento da modernidade na Europa, consolida, com a assinatura da Paz de Westfália ${ }^{3}$, em 1648, uma nova forma de organização social forjada a partir de elementos como a homogeneidade, identidade, pertencimento, nacionalismo, entre outras. Se formam, assim, organizações jurídico-políticas que reúnem um território determinado e uma estrutura administrativa, que se caracterizam, segundo López y Rivas (2014) por possuírem traços culturais comuns como uma língua oficial, a consciência de pertencimento ao grupo e sentimentos patrióticos. Por sua vez, Butler e Spivak (2009) adicionam a essas características que é papel do Estado, ao definir direitos e deveres de seus cidadãos, determinar quais são as condições para se estar juridicamente vinculado a ele.

O surgimento desse modelo de Estado delimita, dessa forma, a existência de um sujeito padrão que, numa perspectiva de homogeneidade, universalização e generalização, é reconhecido como o titular de direitos e obrigações frente ao Estado, acarretando a imposição de sua forma de vida a todos os indivíduos que não se encaixassem nesse padrão. Nesse sentido, afirma López y Rivas:

La homogeneización de la sociedad nacional nunca consistió, de hecho, en una convergencia de las distintas culturas y modos de vida regionales, o uno que los sintetizara, sino en la acción de un sector dominante de la sociedad que, desde el poder

\footnotetext{
${ }^{3}$ A Paz de Westfália compreende uma série de tratados que encerraram a Guerra dos Trinta anos, estabelecendo conceitos como o de Estado-nação e o de soberania nacional. 
central, impuso su forma de vida sobre los demás. Los nuevos Estados nacionales se forman a partir del programa decidido por un sector social que se propone la transformación del antiguo régimen para formar uma sociedad homogénea (LOPES Y RIVAS, 2014, p.3 $)^{4}$.

A padronização dos sujeitos é essencial para a manutenção desse Estado moderno nascente. Dessa forma, a generalização e universalização revela o sujeito eleito pelo Estado, que pouco vai mudar em atributos desde o advento desse modelo de Estado na Europa até os dias atuais na América Latina: o homem dotado de capacidade de produzir e circular riquezas é o sujeito de direito que vai ser o fim último da ação do Estado. O homem dotado de capacidade econômica plena e de autodeterminação, numa perspectiva liberal é o destinatário dos direitos e deveres na arena estatal.

Todos os demais indivíduos que fogem a esses atributos - mulheres, os menores, os analfabetos, os povos tradicionais - não são do interesse do Estado, consolidando um processo de exclusão e negação de certos grupos da sociedade conforme retrata López y Rivas:

De estos procesos modernizadores que dan origen a los Estados-nación, se genera la exclusión y negación de aquellos sujetos sociales y políticos pertenecientes a las etnias históricas y pueblos originales sobre los cuales se erigen los proyectos hegemonicos emergentes (LOPES Y RIVAS, 2014, p. 3-4) ${ }^{5}$.

O modelo de Estado-nação moderno é, assim, criado com base numa prática de negação de direitos, que utiliza a linguagem de forma hegemônica, buscando eliminar a diversidade cultural, alisar o tecido social pela homogeneidade e pela uniformidade cultural. Isso se dá pelo afastamento dos fatores culturais, o que permite identificar soberania e comunidade ou “imaginar” grupos de pessoas culturalmente homogêneos. Dá-se, ainda, pela crença na uniformidade e pela centralização das estruturas políticas o que permite acreditar na igualdade entre cidadãos. Nesse sentido, afirma Ashis Nandy:

[...] cada Estado-nación empezó a considerarse um depósito de valores culturales específicos, cuando em realidad buscaban equiparar esos valores com um concepto territorial de nacionalidad que incidía contra el significado más amplio de cultura, que

\footnotetext{
${ }^{4}$ A homogeneização da sociedade nacional nunca foi, de fato, uma convergência de diferentes culturas e modos de vida regionais, sintetizando-os, mas a ação da classe dominante de uma sociedade que, desde o poder central, impôs seu modo de vida sobre os outros. Os novos Estados nacionais são formados a partir do programa decidido por uma classe social que propõe a transformação do antigo regime para formar uma sociedade homogênea (tradução livre do autor)

${ }^{5}$ Estes processos de modernização que dão origem aos Estados-nação, criam exclusão e negação dos sujeitos sociais e políticos pertencentes a etnias históricas e povos originais sobre os quais se fundam os projetos hegemônicos emergentes (tradução livre do autor).
} 
inherentemente no podía circunscribirse dentro de limites territoriales (NANDY, 2011$, p. 21$)^{6}$.

Ainda nessa linha, Butler e Spivak apontam a contradição no fato de os Estados atuarem no sentido de negação dos direitos de suas próprias minorias nacionais: “[...] Hay mucho em juego cuando consideramos cómo pensar mejor el estado-nación como una formación politica que requiere de la expulsión periódica y la desposesión de sus minorias nacionales para obtener um fundamento que lo legitime" (BUTLER; SPIVAK, 2009, p. 66). ${ }^{7}$

$\mathrm{Na}$ América Latina esse modelo de Estado é introduzido pelo processo de conquista/colonização, com contornos semelhantes aos de sua criação. Todavia, é importante destacar que a tentativa de aplicação dos padrões dos sujeitos capazes do Estado europeu à realidade latino-americana caracterizou episódios com consequências, na maioria das vezes, muito mais graves, em razão da gritante diferença entre os atributos dos sujeitos capazes no Estado Moderno e aqueles que construíam as identidades e racionalidades das sociedades ameríndias pré-conquista.

Na tentativa de implantar essa moldura num retrato que não correspondia às suas dimensões, as metrópoles ora se utilizavam da estratégia de marginalização e invisibilização dos grupos que aqui já habitavam e se constituíam numa perspectiva diametralmente oposta no tocante aos seus valores, modos de vida e estruturas organizativas e ora, na tentativa de cooptar e transformar esses sujeitos e grupos aos moldes do sujeito ao qual o Estado europeu, o resultado foi nefasto: grupos e populações foram dizimadas. Esse processo de legitimação da ideia de Estado-nação na colônia latino-americana é retratada por Nandy:

La idea del Estado-nación llegó a la mayoría de las sociedades del sur a través de la conexión colonial, montada em el concepto de la carga del hombre blanco. Cuando después de la descolonización las elites autóctonas se hicieran del control del aparato del Estado, aprendieron rápidademnte a buscar la legitimidad em uma versión nativa de la missión civilizadora e intentaron estabelecer uma relación colonial similar entre Estado y la sociedad (NANDY, 2011, p. 27-28) ${ }^{8}$.

\footnotetext{
${ }^{6}$ Cada Estado-nação começou a considerar-se um depósito de valores culturais específicos, quando na realidade procurou equiparar esses valores com um conceito territorial nacionalidade que foi contra o significado mais amplo da cultura, que inerentemente não podia limitar-se dentro dos limites territoriais (tradução livre do autor).

${ }^{7}$ Há muito em jogo quando consideramos como estado-nação como uma formação política que exige a expulsão periódica e desapropriação de suas minorias nacionais para obter um fundamento que o legitime (tradução livre do autor).

${ }^{8}$ A ideia do estado-nação chegou à maioria das sociedades do Sul através da conexão colonial, montado no conceito de valor do homem branco. Quando depois da descolonização as elites nativas tomaram o controle do aparelho de estado, eles aprenderam rapidamente a buscar legitimidade numa versão nativa da de missão civilizadora e tentaram estabelecer uma relação colonial semelhante entre Estado e sociedade (tradução livre do
} autor). 
O caso retratado por Taussig (2015), na sua Magia do Estado é um exemplo dessa tentativa de legitimação da ideia do Estado-nação na Venezuela, a partir da estratégia de conectar símbolos que representam o popular e o Estado, fomentando a ideia de nação desde as relações entre Simón Bolívar, cuja onipresença é legitimada pelo Estado e Maria Lionza, presente no pensamento dos peregrinos da montanha. Para que o zEstado se legitime entre os grupos e comunidades locais ele utiliza a magia que o primitivismo possui enquanto formador essencial da noção de nação, sendo a união do símbolo Estatal ao símbolo popular formadora do sentido de pertencimento e identidade nacional.

No entanto, apesar das mais variadas tentativas de legitimação da noção de Estadonação a partir de políticas que variam entre a assimilação e integração, entre a segregação e a reprodução das diferenças (LÓPEZ Y RIVAS, 2014), muitos são os problemas atuais que colocam em xeque a ideia de Estado, demonstrando a insuficiência desse modelo na representação das diversidades e em responder a questionamentos que emergiram nos últimos tempos: “[...] ¿qué es um estado-nación? (y su reverso, ¿qué es um estado sin nación, o uma nación sin estado, como la palestina?)? [...] ¿Qué es ser um ciudadano (y su reverso ¿qué es ser um sin-estado?) (BUTLER; SPIVAK, 2009, p. 32-33) ${ }^{9}$.

Nesse sentido, Ashis Nandy (2011) propõe que da mesma forma em que se verifica uma crise na ideia de Estado-nação, por se tratar de uma organização social tão fundamental, não é possível estabelecer ao certo outras estruturas que possam substituí-lo nem, tampouco, se o conceito estruturante da ideia de Estado será repensado “[...] si no como respuesta a las dudas y criticas intelectuales, si cuando menos em respuesta a los amplios procesos de democratización y globalización que tienen lugar en el mundo" (NANDY, 2011, p. 33) ${ }^{10}$.

Certamente, alternativas a esse modelo vem sendo pensadas, demandas por grupos e populações que, cada vez mais organizados, fazem avançar sua agenda de luta por autonomia e conquista de direitos. Soluções como o Estado multinacional, multiétnico y multicultural, segundo Nandy (2011), são respostas elaboradas para superar e corrigir a noção de Estadonação unitário. Gruner, prefaciando Butler e Spivak (2009), aponta que situações como a Bolívia de Evo Morales, um Estado-nação multiétnico e multilinguístico, com uma língua oficial, mas onde se fala inúmeras outras relacionadas aos seus povos tradicionais e originários,

\footnotetext{
${ }^{9} \mathrm{O}$ que é um estado-nação? E seu inverso, o que é um estado sem nação ou uma nação sem estado, como a Palestina? O que e ser um cidadão? E seu inverso o que é ser uma pessoa sem pátria? (tradução livre do autor).

${ }^{10}$ Se não como uma resposta para as dúvidas dos intelectuais e críticos, nem menos como resposta aos amplos processos de democratização e globalização ocorrendo no mundo afora (tradução livre do autor).
} 
aponta para a necessidade de continuar repensando a figura do Estado a partir das dimensões da democracia comunitária e da afirmação da interculturalidade como fator essencial da identidade dos Estados nacionais latino-americanos.

\section{II - AS LUTAS POR AUTONOMIA E DIREITOS E A DEMOCRACIA COMUNITÁRIA COMO PROJETO}

Diante da dominação característica do modelo de Estado-nação forjado pela modernidade e replicado na América Latina com a colonização e o respectivo questionamento de suas bases homogeneizadoras e marginalizadoras, os povos originários e tradicionais latinoamericanos, na tentativa de se estabelecerem de forma autonômica e/ou constituírem novas relações com a estrutura estatal, marcam novas posições ao propor modelos de democracia comunitária como projeto de sua organização social. Centradas na noção de autonomia, são processos de resistência dos não-sujeito do Estado-nação moderno, como assevera Gilberto López y Rivas:

Las autonomias, tal y como las concebimos em nuestra América Latina son processos de resistência em los cuales etnias, pueblos y naciones soterradas o negadas recuperan o fortalecen su identidade mediante la reinvidicanción de su cultura, ele ejercicio de Derechos colectivos y el estabelecimento de estructuras politico-administrativas com ámbitos y competencias propios (LÓPEZ Y RIVAS, 2014, p.6) ${ }^{11}$.

Essas lutas por autonomia e garantia de direitos são construídas num sentido de descolonização desse modelo de Estado, uma vez que o fim do período colonial não representou o rompimento da influência dos modelos pensados para a realidade europeia e que foram aqui implantados impositivamente. Tais lutas são, então, esforços desprendidos no sentido de questionar o caráter colonial/eurocêntrico dos saberes e das estruturas (inclusive do Estado!), já que, na perspectiva da Colonialidade do Saber vislumbra-se que para além da desigualdade e injustiça resultantes do processo de colonização, “[...] há um legado epistemológico do eurocentrismo que nos impede de compreender o mundo a partir do próprio mundo em que vivemos e das epistemes que lhes são próprias" (LANDER, 2005).

Conforme ensina Mignolo (2006), esse projeto de América Latina que rompe com as categorias da modernidade e da colonialidade só é possível a partir do pensamento descolonial,

\footnotetext{
${ }^{11}$ As autonomias, como os concebemos em nossa América Latina são processos de resistência nos quais grupos étnicos, povos e nações enterrados ou negado passam a recuperar ou reforçar a sua identidade através da reivindicação de sua cultura, do exercício de direitos coletivos e da criação de estruturas políticas e administrativas com espaços e competências próprias (tradução livre do autor).
} 
uma vez que é essa a lente que nos possibilita enxergar para além dos essencialismos e dogmas estruturais que fundamentam as relações sociais nos Estados modernos latino-americanos, vislumbrando a confiança de que outros mundos são possíveis, afirmando a não homogeneidade de grupos e comunidades que, na imposição de modelos e padrões dominantes e de controle “[...] simplemente dicen: 'no gracias, pero no, no me interessa ser incluido em su modelo de sociedad, de economia, de epistemologia y de subjetividad"' (MIGNOLO, 2006, p.12) ${ }^{12}$.

Essas são as premissas para o que Mignolo vai chamar de Giro Descolonial, o rompimento com o sistema de relações desiguais entre Norte e Sul utilizado com o único possível para a compreensão do mundo contemporâneo, uma vez que "[...] Tais relações foram construídas historicamente pelo colonialismo e o fim do colonialismo enquanto relação política não acarretou o fim do colonialismo enquanto relação social enquanto mentalidade e forma de sociabilidade autoritária e discriminatória” (SANTOS, 2002). Nesse sentido,

El giro descolonial consiste em desprenderse del chaleco de fuerza de las categorias de pensamento que naturalizan la colonialidad del saber y del ser y la justifican em la retorica de la Modernidad, el progresso y la gestión 'democrática' imperial (MIGNOLO, 2006, p.13) ${ }^{13}$.

Esses processos autonômicos, na lógica da descolonização, são construídos processualmente, como resultado das demandas próprias dos vários sujeitos marginalizados na estrutura estatal que, negando as relações de dominação pelas quais se estrutura o Estado-nação, vão se constituindo enquanto grupo organizado, demandando participação e inserção nos espaços políticos, econômicos, culturais e sociais nos mais diversos níveis do Estado, de modo a garantir e preservar sua própria identidade.

Outrossim, é importante destacar que as lutas por autonomia podem assumir diversas naturezas. López y Rivas (2014) afirma a possibilidade dessas lutas se constituírem em bases/ dimensões étnica, racial ou nacional. No caso da América Latina, por força da ordem colonial que suplantou a autonomia de diversos povos ao inseri-los nos moldes do Estado moderno, a maioria das reivindicações são fundadas nos fatores étnicos e culturais e se configuram no interior dos estados-nação a partir da oposição dos grupos étnicos e dos grupos étniconacionais:

\footnotetext{
${ }^{12}$ Simplesmente dizem: não, obrigado, mas não, não me interessa ser incluido em seu modelo de sociedade, de economia, de epistemologia e de subjetividade (tradução livre do autor).

${ }^{13} \mathrm{O}$ giro decolonial consiste em se livrar da camisa de força das categorias de pensamento que naturalizam o colonialismo do saber e do ser e justificam-na na retórica da modernidade, no progresso e na gestão democrática imperial (tradução livre do autor).

CONPEDI LAW REVIEW | QUITO - EQUADOR | v. 4 | n. 2 | p. 297 - 313 | JUL - DEZ | 2018 
Los grupos étnicos constituyen sistemas socioculturales diferenciados em el interior de la nación, basados em estructuras de organización comunal. Generalmente son grupos cuyo origen linguistico se remonta a um tempo histórico precapitalista y em los que se da uma importancia reativa, em la organización socioeconômica, a las relaciones de parentesco; asimismo, tenemos el predominio y la tendencia a la endogamia.

$[\ldots]$

Los grupos étnico-nacionales, si bien pueden basar su organización social em estructuras comunales y compartir muchos de los rasgos de los grupos étnicos, han alcanzado um grado de desarrollo sócio-politico que rebasa el ambito de la comunidad o pueblo. Lo basico es que, como resultado de un proceso histórico que implica cierto grado de diferenciación social, impactos economicos, conformación de um sistema ideológico cohesionado y surgimiento de una elite intectual representativa, entre otros factores, el grupo étnico-nacional es capaz de cristalizar una percepción de la identidad propia em tanto unidad integral de todas las comunidades o pueblos que poseen elementos socioculturales comunes.

Las identidades diferenciadas de los grupos étnicos nacionales en relación a la nacionalidad dominante o mayoritaria, y al Estado nacional respectivo, van conformando proyectos étnicos que se expresan em los ámbitos nacionales de lucha por la hegemonia, a traves del planteamiento de diferentes reivindicaciones que van desde las agrarias y culturales, hasta las de autonomía (LÓPEZ Y RIVAS, 2014, p. $12-14)^{14}$.

Como exemplo de luta por autonomia, o movimento Zapatista mexicano se destaca pelas iniciativas e experiências dos indígenas neozapatistas da região do Chiapas, se constituindo enquanto grupos que fortalecem sua identidade por meio da reivindicação de sua cultura, do exercício dos seus direitos coletivos e do estabelecimento de estruturas jurídico-administrativas com espaços e competências próprios, os governos autônomos, que pretendem, a partir da criação de um Estado plural, se movimentar por outras vias que não a homogeneizadora liberal. López y Rivas (2014) destaca que os objetivos do movimento zapatista passam pela fundação de uma sociedade em que a comunidade tenha a responsabilidade, o direito, os mecanismos e as oportunidades para se autogovernar, ou seja, passar a ser protagonistas da mudança social e não meros espectadores.

${ }^{14}$ Grupos étnicos constituem sistemas culturais diferenciados dentro da nação, com base em estruturas de
organização comunal. Eles são geralmente grupos cuja origem linguística remonta o período pré-capitalista e dá
uma importância de subvenções, organização socioeconômica, relações de parentesco; além disso, temos o
domínio e a tendência para a endogamia. [...] Grupos nacionais, enquanto podem basear suas estruturas comuns
em de organização social e compartilham muitas das características dos grupos étnicos, alcançaram um grau de
desenvolvimento sócio-político que vai além do escopo da Comunidade ou aldeia. O básico é que, como resultado
de um processo histórico que envolve algum grau de diferenciação social, formação, impacto econômico num
sistema ideologicamente coesivo e surgimento de uma elite intelectual representativa, entre outros fatores, o grupo
nacional é capaz de cristalizar uma percepção da própria identidade tanto unidade integral de todas as comunidades
ou povos que possuem elementos culturais comuns. Identidades distintas de grupos nacionais em relação a
dominante ou nacionalidade da maioria e o respectivo Estado nacional, são conformes áreas nacionais étnicos em
expressa da luta pela hegemonia, pela configuração de reivindicações diferentes que vão desde os projetos
agrícolas e culturais, até a autonomia (tradução livre do autor). CONPEDI LAW REVIEW | QUITO - EQUADOR | v. 4 | n. 2 | p. 297 - 313 | JUL - DEZ | 2018 
Numa perspectiva menos autonômica que a do Exército Zapatista de Libertação Nacional, mas que, da mesma forma, pretende repensar a proposta de Estado moderno liberal, as experiências de lutas dos povos e comunidades tradicionais do Equador e da Bolívia pela afirmação das diferenças e reconhecimento das mesmas no seio estatal são as sementes dos processos constituintes que reconhecem novos sujeitos de direito e novos direitos no novo constitucionalismo democrático latino-americano.

O caso equatoriano, segundo Walsh (2006), revela um processo de construção de novas alternativas centradas a partir da significação da interculturalidade, de um pensamento insurgente e de metas estrategicamente políticas. Assim é pautada a luta tanto do movimento indígena quanto dos povos afroequatorianos.

O movimento indígena, por meio a Confederação de Nacionalidades Indígenas de Ecuador - CONAIE, possui um projeto político que reivindica a construção política, ideológica e epistêmica da interculturalidade, enquanto a chave para a consolidação de um Estado Plurinacional no Equador, o que se verificaria com a promulgação da constituição equatoriana de 2008. Esse objetivo se concretiza, por exemplo, por meio da organização da Universidade Intercultural Amawatay Wasi, que, da perspectiva das populações indígenas tem a tarefa, segundo Walsh (2006) de repensar, reconstruir e rearticular o conhecimento e pensamento andino ancestral. Do outro lado, e no mesmo sentido, os afroequatorianos visam a construção de um pensamento e uma prática outros, a partir da mobilização das categorias que mobilizam com seus modos próprios de vida.

Por sua vez, a experiência da construção da transição entre um modelo de democracia e Estado liberal para uma matriz de democracia comunitária da Bolívia, vai consolidar, com a promulgação do texto constitucional que inaugura o Estado Plurinacional da Bolívia em 2009, avanços na garantia das inúmeras racionalidades e modos de vida dos povos tradicionais que compõem o Estado boliviano. Linera (2006) retrata esse processo a partir do contexto da guerra da água e do gás (em 2000 e 2003, respectivamente) e da eleição do líder sindical de origem Ayamara, Evo Morales, em 2005, a partir da transição de um Estado monoorganizativo para um Estado pluridiverso baseado no reconhecimento constitucional dos diversos sistemas políticos e de autoridade praticados pelas comunidades campesinas; na eleição de representantes de todos os grupos para comporem o parlamento e na obrigatoriedade de reconhecimento de todos os povos acerca dos temas centrais da gestão estão, inaugurando uma nova perspectiva de participação num sistema democrático, em via direta. 
Ambas as experiências impulsionaram processos constituintes que tiveram como resultado textos constitucionais que inovam a perspectiva das titularidades no espaço estatal, fundadas a partir de uma perspectiva decolonial e, que reunidas, demonstram uma tendencia que vem se aprofundando nos textos constitucionais dos Estados América Latina afora, o Novo Constitucionalismo latino-americano.

\section{III - ALTERNATIVAS DESDE O NOVO CONSTITUCIONALISMO LATINO- AMERICANO: processos constituintes na América Latina e interculturalidade}

A dificuldade do reconhecimento dos novos sujeitos de Direito que demandam o reconhecimento do Estado a partir da noção de interculturalidade (sujeitos coletivos, diversidades culturais, conhecimentos tradicionais) vem sendo superada em processos constituintes de Estados latino-americanos que ousam ao refundar seus Estados a partir de novas matrizes que não as do Estado moderno clássico, deixando de lado tanto o constitucionalismo liberal monista do século XIX quanto o constitucionalismo social integracionista do século XX. Esses processos constituintes estão categorizados como parte de um movimento de avanço na estruturação do Estado, como parte do chamado Novo Constitucionalismo Latino-americano.

Esse movimento é caracterizado pela refundação do Estado baseada na compreensão do fenômeno jurídico-constitucional a partir dos enfoques plurais das sociedades, vislumbrando e reconhecendo, a partir da perspectiva da interculturalidade, novos sujeitos e novos direitos aos sujeitos marginalizados na estrutura do Estado, se consolidando com a promulgação das Constituições da Venezuela (1999), do Equador (2008) e da Bolívia (2009). O advento desse novo movimento é caracterizado, então, a partir dos processos constituintes latino-americanos e tem enquanto destaques as relações entre Estado e os povos tradicionais/originários, no sentido de valorização da diversidade cultural, e os direitos relacionados à natureza.

Nesse sentido é possível perceber um avanço processual na compreensão da diversidade enquanto elemento central nos processos constituintes latino-americanos, conforme sistematiza Raquel Yrigoyen Fajardo, que divide esse processo em três ciclos (BRANDÃO, 2015): O constitucionalismo multicultural, que tem como principais características a abertura das constituições para a diversidade cultural e o reconhecimento das várias línguas oficiais. São exemplos desse ciclo as constituições da Guatemala, de 1985, que reconhece a configuração multiétnica e multicultural do país, a constituição da Nicarágua, de 1987, que declara a natureza multiétnica do povo e seus direitos culturais, linguísticos e territoriais e a brasileira de 1988; O 
constitucionalismo pluricultural, que foi influenciada pela Convenção 169 da OIT, e tem como principal característica e introdução de fórmulas de pluralismo jurídico que rompem com a ideia de monismo jurídico e, consequentemente passam a reconhecer a as tradições, costumes e autoridades indígenas. São exemplos desse novo ciclo as constituições da Colômbia (1991), México (1992) Peru (1993) Equador (1998) e Venezuela (1999); c) O constitucionalismo plurinacional, marcado pelo giro paradigmático na organização do direito e do Estado, uma vez que não só reconhece e positiva os direitos indígenas, mas internaliza o conhecimento e a cosmovisão indígena nesse processo. É representada pelas Constituições do Equador de 2008 e da Bolívia de 2009, com base na plurinacionalidade e no protagonismo indígena.

Esse novo modelo, no sentido de garantir as diversidades culturais no sentido da interculturalidade, se funda, em sua fase mais evoluída, em elementos da cosmovisão indígena para delimitar o direito nos processos constituintes: as ideias de buen vivir (Sumak Kawsay dos Quéchua e nãnde reko dos guarani) e Pachamama, são exemplos de categorias dessa cosmovisão inseridas na matriz de organização do Estado.

A propriedade coletiva da terra dos povos tradicionais é consagrada na Convenção 169 da OIT, no seu artigo $13^{15}$. Sobre esse caráter coletivo da propriedade, afirma Carlos Marés que os países com ordenamentos constitucionais que anteriormente não reconheciam a pluriculturalidade e a multietnicidade, passaram a reconhecer que "[...] têm uma variada formação étnica e cultural, e que cada grupo humano que esteja organizado segundo sua cultura e viva segundo sua tradição, em conformidade com a natureza da qual participa, tem o direito à opção de seu próprio desenvolvimento" (MARÉS, 2010, p. 93). Assim, conclui que “[...] esses novos direitos têm como principal característica o fato de sua titularidade não ser individualizada" (MARÉS, 2010, p. 93).

Quando se fala do direito de propriedade de terras das comunidades tradicionais se considera todo o processo histórico de negação/violação de direitos. A propriedade coletiva é, assim, uma conquista presente nas constituições de diversos países da América Latina, aliando três quesitos: coletividade, inalienabilidade e titularidade do território. Rios destaca, ainda, que o caráter coletivo da propriedade não surge de uma relação jurídica formal, “[...] mas da experiência comunitária de um povo que prevê a garantia de vida, do cultivo da terra livre de

\footnotetext{
${ }^{15}$ A convenção 169 da OIT, em seu artigo 13 dispõe que o conceito de território, abrange a totalidade do habitat das regiões que as comunidades quilombolas ocupam ou utilizam de alguma outra forma.
} 
qualquer forma de ganância e da possibilidade de comércio da propriedade, da moradia, e a certeza da continuidade da vida das famílias, dos parentes e dos vizinhos" (RIOS, 2008).

A concepção de terra enquanto espaço de cultivo do bem viver, vem sendo adotada a partir da consciência das pessoas de que o ser “[...] humano não é autossuficiente frente a terra, mas que sua vida depende de uma terra viva e sadia" (CHAMBE, 2013). Nesse sentido, a expressão Pachamama, que significa a Mãe Terra, na perspectiva do sentimento de cuidado com o espaço que nos garante a vida.

Esse conhecimento e tratamento para com o território ocupado, que é uma característica marcante do Constitucionalismo Latino-americano, sempre esteve presente na mentalidade dos povos tradicionais, sobretudo dos indígenas. Assim, propõe Juan Chambe que a relação da comunidade com o seu espaço (território) “[...] não fomenta um acúmulo e consumo desenfreado, mas o necessário para viver dignamente, pois são partes de algo mais vasto, parte do círculo natural da vida, pelo qual uma ação que destrua a terra é um suicídio" (CHAMBE, 2013).

Tal postura advinda do surgimento dessa nova matriz constitucional latino-americana reconhece o esgotamento do ambiente e de suas fontes frente ao modelo de produção imposto pelo mercado e atribui direito à natureza, motivo pelo qual ela deve ser protegida e cuidada conforme as práticas das comunidades tradicionais. Essa convivência harmônica é a expressão do Buen vivir" ${ }^{16}$. Sobre este, Germana Moraes pondera que é "[...] um campo de ideias em construção, que está se difundindo em toda a América Latina e pode criar ou co-criar novas conceitualizações adaptadas às circunstâncias atuais" (MORAES, 2008). E complementa que esse campo "aspira ir mais além do desenvolvimento convencional e se baseia em uma sociedade onde convivem os seres humanos entre si e com a natureza" (MORAES, 2008).

O buen vivir, assim, segundo Rubén Martinez Dalmau, é um conceito estruturante desse novo padrão constitucional latino-americano (DALMAU, 2013, p. 55). Esse conceito estruturante demonstra possibilidades sociais, políticas e jurídicas abertas na América Latina. Tais possibilidades foram negadas/invisibilizadas aos sujeitos não enquadrados dentro do paradigma moderno. As comunidades tradicionais e a natureza (agora, sujeito de direito) demandam olhares e posturas diversas, específicas à formação social, política e econômica a

16 Tradução literal do quéchua (língua indígena sul-americana) “Sumak Kawsay”, que significa boa vida, no sentido de uma "cosmovisão de harmonia das comunidades humanas com a natureza, no qual o ser humano é parte de uma comunidade de pessoas que, por sua vez, é um elemento constituinte da mesma pachamama ou pachamama" (MARÉS, 2010). 
elas. Demandam, principalmente, participação dentro do Estado para a construção e efetivação de direitos coerentes às suas realidades.

\section{CONSIDERAÇÕES FINAIS}

No dia de hoje do ano de 2009, um plebiscito popular disse sim à nova Constituição proposta pelo presidente Evo Morales.

Até este dia, os índios não eram filhos da Bolívia: eram sua mão de obra, e só.

Em 1825, a primeira Constituição outorgou a cidadania a três ou quatro por cento da população. Os demais - índios, mulheres, pobres, analfabetos - não foram convidados para a festa. Para muitos jornalistas estrangeiros, a Bolívia é um país ingovernável, incompreensível, intratável, inviável. São os que se enganaram de in: deveriam confessar que a Bolívia, para eles, é um país invisível. E não há nada de estranho nisso, porque até o dia de hoje também a Bolívia foi um país cego de si.

- Segunda fundação da Bolívia, Eduardo Galeano

Apesar dos avanços, muitos são os desafios a serem superados na garantia dos direitos e na afirmação da autonomia nos Estados latino-americanos, sobremaneira no plano da efetividade dos direitos conquistados com base na noção de interculturalidade e na ampliação dessas garantias já asseguradas em diversos processos constituintes dos últimos 30 anos na América Latina.

Algumas luzes no sentido de incorporar o imperativo da interculturalidade de forma ampla, integral e efetiva são percebidas desde os processos constitucionais do Novo Constitucionalismo Latino-americano, uma vez que os mesmos refundam o Estado e o direito com base em matrizes mais sensíveis à diversidade, como o buen vivir.

Em se tratando da interculturalidade enquanto um imperativo ético de sociedades que possuem uma pluralidade de grupos que se manifestam e organizam das mais variadas formas, a dinâmica dos movimentos, instituições e direitos demandaram, demandam e demandarão a superação da noção de igualdade e do sujeito atomizado e capaz conforme os primados da Revolução Francesa, fazendo avançar essa noção de igualdade da modernidade que tem um padrão e um destinatário para uma igualdade complexa fundada na diversidade, assegurando os mais distintos modos de fazer, viver e criar dos povos originários e tradicionais da latinoamérica! 


\section{REFERÊNCIAS}

ABRAMS, Philip. Notas sobre la dificultad de estudiar el estado. In: ABRAMS, Philip; GUPTA, Akhil; MITCHELL, Timothy. Antropología del Estado. Mexico: FCE, 2015.

BRANDÃO, Pedro. O novo constitucionalismo pluralista latino-americano. Rio de Janeiro: Lumen Juris, 2015.

BUTLER, Judith; SPIVAK, Gayatri Chakravorty. ¿Quién le canta al Estado-nación? Lenguaje, política, pertenencia. Buenos Aires: Paidós, 2009

CHAMBE, Juan Jacobo Tancara. O regresso à Pachamama. Disponível em: $<$ http://www.servicioskoinonia.org/agenda/archivo/portugues/obra.php?ncodigo $=302>$. Acesso em 11.ago.2016.

DALMAU, Rubén Martinez; PASTOR, Roberto Viciano. O processo constituinte venezuelano no marco do novo constitucionalismo latino-americano. In: WOLKMER, Antônio Carlos. Constitucionalismo latino-americano: tendência contemporânea. Curitiba: Juruá, 2013

DUSSEL, Enrique. 20 Teses de Política. São Paulo: Expressão Popular, 2007.

EQUADOR. Constitucion de la Republica del Ecuador de 2008.

GALEANO, Eduardo. Segunda Fundação da Bolívia. In: GALEANO, Eduardo. Os filhos dos dias. Tradução de Eric Nepomucenoo. Porto Alegre: LP\&M, 2014.

LANDER, E. (Org.). A colonialidade do saber: eurocentrismo e ciências sociais. Perspectivas latino-americanas. Tradução de Júlio César Barroso Silva. Buenos Aires: CLACSO, 2005.

LINERA, Alvaro Garcia. Democracia Liberal vs. Democracia Comunitária. In: WALSH, Catherine; LINERA, Alvaro Garcia; MIGNOLO, Walter. Interculturalidad, descolonización del Estado y del conocimiento. Buenos Aires: Del Signo, 2006.

LÓPEZ Y RIVAS, Gilberto. Autonomía de los pueblos indios y zapatismo em México. México: Ocean Sur, 2014.

MARÉS, Carlos Frederico. Multiculturalismo e direitos coletivos. In: SANTOS, Boaventura de Sousa. Reconhecer para libertar. Os caminhos do cosmopolitismo multicultural. Rio de Janeiro: Civilização Brasileira, 2010

MIGNOLO, Walter. El desprendimiento: pensamento critico y giro descolonial. In: WALSH, Catherine; LINERA, Alvaro Garcia; MIGNOLO, Walter. Interculturalidad, descolonización del Estado y del conocimiento. Buenos Aires: Del Signo, 2006.

MORAES, Germana Oliveira de. O constitucionalismo ecocêntrico na América Latina, o Bem viver e a Nova visão das águas. Revista da Faculdade de Direito da Universidade Federal do Ceará. Disponível em: 
$<\mathrm{http}: / /$ www.revistadireito.ufc.br/index.php/revdir/article/view/11/13>. Acesso em 15.ago. 2016

NANDY, Ashis. Imágenes del Estado: cultura, violencia y desarrollo. México: FCE, 2011.

RIOS, Mariza. Território Quilombola: uma propriedade especial. Disponível em:

$<$ www.domtotal.com/direito/pagina/detalhe/23806/territorioquilombolaumapropriedadeespeci al>. Acesso em: 10.ago.2016

SANTOS, Boaventura de Sousa. Do pós-moderno ao pós-colonial. Abertura da Conferência Luso Brasileira, 2002, Disponível em: http:/www.ces.fé.uc/misc/Do_pos-moderno_ao_póscolonial.pdf. Acesso em 21.ago.2014.

TAUSSIG, Michael. La magia del Estado. México: Siglo XXI, 2015.

WALSH, Catherine. Interculturalidad y colonialidad del poder. Un pensamiernto y posicionamiento otro desde la diferencia colonial. In: WALSH, Catherine; LINERA, Alvaro Garcia; MIGNOLO, Walter. Interculturalidad, descolonización del Estado y del conocimiento. Buenos Aires: Del Signo, 2006. 